\section{Tranexamic Acid Use and Post Operative Outcome in Patients Undergoing Spine Surgery for Scoliosis in An-Najah National University Hospital / Palestine: A Prospective, Randomized, Double Blinded Study}

\section{Abstract}

Context: Some reports have been published regarding the effectiveness of Tranexamic acid (TXA) on reducing blood loss and blood transfusion in patients undergoing orthopedic and major orthopedic surgery

We performed a prospective randomized control study to evaluate the effectiveness and safety of preoperative tranexamic acid use on blood transfusion, thromboembolic events and mortality in patients undergoing spinal surgery for scoliosis in An-Najah National University Hospital in Palestine.

Materials and Methods: A prospective, randomized, double blinded study was conducted in the tertiary care teaching hospital. the weighted mean difference in blood loss, number of transfusions per patient, and the risk ratio of transfusion and deep vein thrombosis (DVT) were calculated in the tranexamic acid (TXA) treated group and the control group .

Hundred ASA grade 1-11 patients undergoing spinal surgery for scoliosis were included in this prospective study. Fifty patients received Tranexamic acid (TXA) given in a bolus dose of $10 \mathrm{mg} / \mathrm{kg} 15$ minutes before surgical incision followed by $10 \mathrm{mg} / \mathrm{kg}$ every 3 hours. The remaining fifty patients were allocated as a control group. Postoperative bleeding (volume of blood in the drain), percentage fall of hemoglobin, transfusions and postoperative complications were recorded.

Results: Mean volume of blood in the drain was $940 \pm 495 \mathrm{ml}$ ( mean \pm SD) as compared to $1450 \pm 740 \mathrm{ml}$ in placebo group showing a $p<0.001$. Mean percentage fall in $\mathrm{Hb}$ at day 0 was $3.2 \pm 2.1$ in the study group as compared to $8.8 \pm 3.0$ in the placebo group $(p<0.001)$, and fall at day two in the study group was $1.1 \pm 0.4$ compared to $3.8 \pm 2.7$ in the placebo group $(p<0.001)$.

The number of patients required blood transfusions were lower in the study group than in placebo group $(p=0.01)$.

Conclusion: Tranexamic acid significantly reduces postoperative blood loss and blood transfusion requirements during spinal surgery for scoliosis correction.

Keywords: Tranexamic acid; Blood transfusion; Postoperative bleeding

\author{
Wael Abdullah Sadaqa ${ }^{1}$ \\ An-Najah National University, Nablus, \\ Palestinian Territory, Occupied, UAE \\ Corresponding author: \\ Wael Abdullah Sadaqa
}

An-Najah National University, Nablus, Palestinian Territory, Occupied. UAE.

ほ w.sadaqa@najah.edu

Citation: Sadaqa WA. Tranexamic Acid Use and Post Operative Outcome in Patients Undergoing Spine Surgery for Scoliosis in An-Najah National University Hospital / Palestine: A Prospective, Randomized, Double Blinded Study. J Biomed Sci. 2016, 5:1. 


\section{Introduction}

Reducing blood loss and the need of blood transfusions in spinal surgery remains a major concern among clinicians during the preoperative period. Many interventions have been developed over the past decades to achieve this goal, including controlled hypertensive anesthesia, and various blood salvage techniques. In addition, pharmacologic approaches have become more popular in recent years. Especially, tranexamic acid has seen a renaissance among patients requiring scoliosis surgery, with numerous publications showing clinical efficacy and cost effectiveness. Indeed a recent study found that the use of tranexamic acid may even make the use of blood salvage equipment unnecessary. Despite these promising results, valid data on safety are lacking, as large sample sizes are needed to determine this outcome. Thus concerns about the routine use of tranexamic acid remain. Data on preoperative outcomes, especially those related to thromboembolic events and renal complications, which have traditionally been of concern in the setting of antifibrinolytic use, are rare. Further, no population based data were available detailing outcomes in a large cohort outside of randomized controlled trials, which often only include selected patients based on stringent inclusion criteria and are thus not reflective of real world practice and are burdened by low external validity.

Utilizing the hospital database, we compared the characteristics and outcomes between patients receiving tranexamic acid and those that did not and analyzed if the use of tranexamic acid is independently associated with altered odds for blood transfusions and preoperative complications, particularly thromboembolic events and acute renal failure. We hypothesized that the characteristics associated with treated and untreated patients differed, and that tranexamic acid decreases the odds for blood transfusions while not increasing the risk of preoperative complications [1-10].

\section{Methods}

Hundred patients (ASA grade 1/11 patients between the age of 6 and 15 years, weighing 20-60 kg) undergoing spinal surgery for scoliosis, from 01/05/2013 to 03/04/2014. Patients with chronic disease like rheumatoid arthritis, malignancy, history of any previous thromboembolic episodes, hemoglobin $<8 \mathrm{~g} / \mathrm{dl}$ were excluded from the study. The study was approved by the institutional Ethics committee and written informed consent was obtained from each patient.

They were allocated to two groups. Randomization was done by opaque sealed envelope technique.

Group T: patients received injection. TXA $10 \mathrm{mg} / \mathrm{kg}$ body weight.

Group P: patients received physiological saline $1 \mathrm{ml} / \mathrm{kg}$ body weight.

Preoperatively, the hemoglobin concentration, bleeding time, clotting times were measured on the day before operation. All patients in the study group received a bolus intravenous injection of $1 \mathrm{mg} / \mathrm{kg}$ TXA is $50 \mathrm{ml}$ syringe during 10 minutes, about 15 minutes before surgery, and the same dose is repeated every three hours until the surgery is completed patients in the placebo group received normal saline a bolus intravenous injection of $50 \mathrm{ml}$ about 15 minutes before surgery followed by continuous infusion of saline until the surgery is completed. Drug and normal saline were loaded by an independent anesthetist.

Surgery was performed under general anesthesia with Fentanyl 1 $\mathrm{mcg} / \mathrm{kg}$,Midazolam $25 \mathrm{mcg} / \mathrm{kg}$, Propofol $2 \mathrm{mg} / \mathrm{kg}$ and Tracrium $0.5 \mathrm{mg} / \mathrm{kg}$, during induction and Sevoflurane $2.6 \%$ in oxygen, Remifentanil I/V $0.5 \mathrm{mcg} / \mathrm{kg} /$ minute I/V infusion and Propofol I/V infusion $0.1 \mathrm{mg} / \mathrm{kg} /$ minute during maintenance.

Hemodynamic (hear rate, systolic, diastolic, mean arterial blood pressure) was noted through the arterial line starting from preoperative to the second day of surgery. Ringer's solution was used as the replacement fluid for the estimated introperative blood volume lost 3:1 ratio.

There was no significant difference in amount of fluid in both groups. Postoperative hemoglobin concentration (on day 0 and day 2) and volume of blood in the drain when the patient entered into the recovery room on the day of operation were measured. The number of units of packed red cells transfused during the hospital stay was recorded, and any thromboembolic and other complication were documented. A criterion for blood transfusion was a reduction in hemoglobin exceeding $25 \%$ of preoperative level.

For tests of differences between quantitative data, two sided Paired difference tests were used. In the text, data presented as mean \pm standard deviation (SD) and $p<0.05$ are considered significant. The data was analyzed by SPSS [11-17].

\section{Results}

There were no significant difference between the patients with respect to age, sex, duration and type of surgery and preoperative mean hemoglobin concentration. Neither heart rate nor mean arterial blood pressure (MABP) has statistically significant difference or results $(p>0.05)$. As shown in Table 1 and Figures $1 \& 2$.

The drains were removed in the morning of the third postoperative day. Mean volume of blood in the drain was $940 . \pm 495 \mathrm{ml}$ (mean $\pm \mathrm{SD}$ ) as compared to $1450 \pm 740 \mathrm{ml}$ in placebo group showing $(p<0.001)$ showing a highly significant reduction of postoperative blood loss (Figure 2).

Mean volume of the blood in day 0 was $430 \mathrm{ml}$ in placebo group compared to $290 \mathrm{ml}$ in study group and in day two $180 \mathrm{ml}$ in placebo group vs. $90 \mathrm{ml}$ in study group.

Mean percentage fall in $\mathrm{Hb}$ at day 0 was $8.5 \mathrm{~g}$ in the study group as compared to $6.5 \mathrm{~g}$ in the placebo group $(p<0.197)$ making it significant finding (Figure 3). Fall of hemoglobin at day two in the study group was $3.8 \mathrm{~g}$ compared to $1.1 \mathrm{~g}$ in the placebo group $(p<0.001)$.

Table 1 Patient characteristics, laboratory and surgical data.

\begin{tabular}{|c|c|c|c|}
\hline Parameters & Placebo $(\mathbf{n}=\mathbf{5 0})$ & Study $(\mathbf{n = 5 0})$ & P value \\
\hline Age (years) & $10.1 \pm 6.2$ & $11.2 \pm 5.3$ & 0.9 \\
\hline Sex M/F & $30 / 20$ & $30 / 20$ & NA \\
\hline Duration of surgery (min) & $300.7 \pm 12.3$ & $285 \pm 10.7$ & 0.5 \\
\hline Preoperative hemoglobin & $11.2 \pm 1.3$ & $11.1 \pm 1.3$ & 0.2 \\
\hline
\end{tabular}


In our study out of fifty patients, 32 patients who fell in the placebo group required blood transfusion, while 13 patients out of 50 in the study group needed a transfusion $(p<0.01)$. No significant complications like thromboembolic episodes were encountered in both groups Table 2.

This was indicated by volume of blood in the drain and fall in the hemoglobin postoperatively.

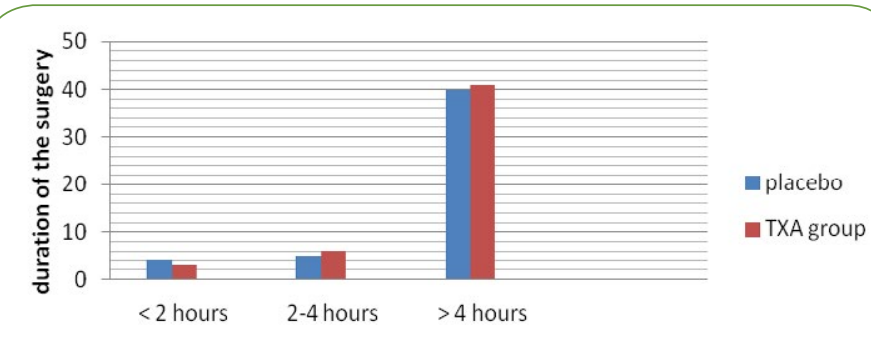

Figure 1 Number of patients.

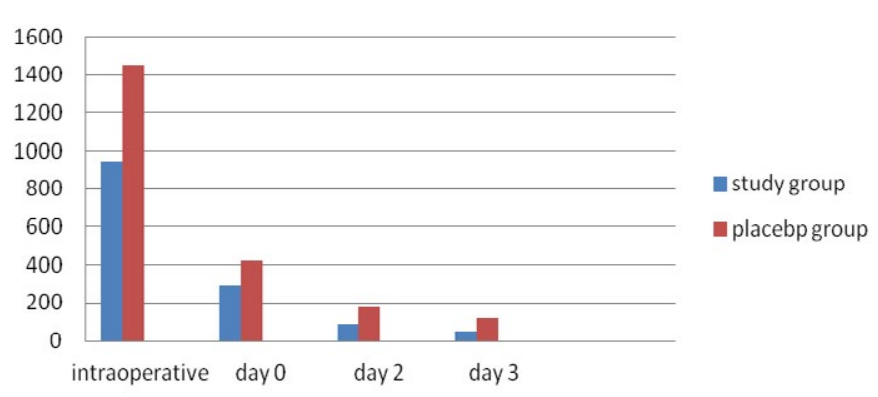

Figure 2 Postoperative volume of blood in the drain.

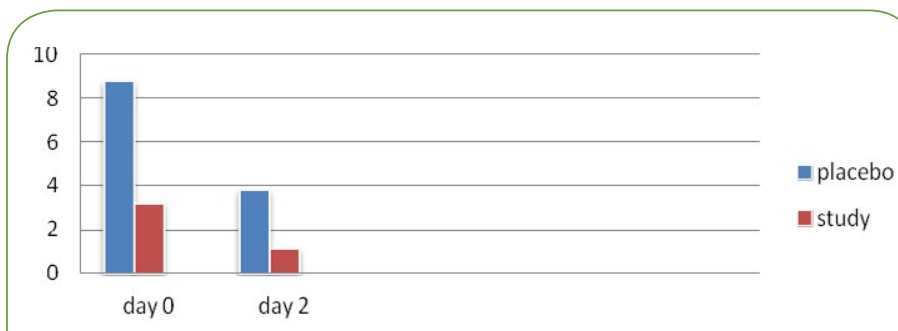

Figure 3 Percentage of fall of mean hemoglobin Concentration.

Table 2. Postoperative volume of blood in drain and \% fall in hemoglobin

\begin{tabular}{|l|c|c|c|}
\hline Parameter & Placebo & Study & P value \\
\hline Volume of blood in drain & $1450 \pm 740 \mathrm{ml}$ & $940 \pm 495 \mathrm{ml}$ & 0.001 \\
\hline Day 0 & $420 \pm 130 \mathrm{ml}$ & $290 \pm 90 \mathrm{ml}$ & 0.197 \\
\hline Day 2 & $180 \pm 90 \mathrm{ml}$ & $90 \pm 50 \mathrm{ml}$ & 0.001 \\
\hline Day 3 & $120 \pm 10 \mathrm{ml}$ & $50 \pm 8 \mathrm{ml}$ & 0.000 \\
\hline Postoperative Hb concentration & & & \\
\hline Day 0 & $8.5 \pm 0.8$ & $0.5 \pm 0.5$ & $02.1 \pm 0.6$ \\
\hline Day 2 & $9.1 \pm 0.5$ & $3.2 \pm 2.1$ & \\
\hline Percentage fall of Hb at day 0 from base line & $8.8 \pm 3.0$ & $1.1 \pm 0.4$ & 0.00 \\
\hline Percentage fall of $\mathrm{Hb}$ at day 2 from day 0 & $3.8 \pm 2.7$ & & 0.00 \\
\hline
\end{tabular}

A similar study was conducted by Sadeghi and Mehraein to see the effect of TXA on hip fracture surgery. They found preoperative blood loss significantly lower in TXA group $(p<0.03)$. The total blood loss was $960 \pm 483 \mathrm{ml}$ in TXA group and $1484 \pm 724 \mathrm{ml}$ in the control group $(p<0.001)$. Postoperative drainage was lower in TXA group ( $296 \pm 85 \mathrm{ml}$ vs. $475 \pm 110 \mathrm{ml}, \mathrm{p}<0.195)$. There were no difference in coagulation parameters. The rate of transfused patients in TXA group 37\% and 57\% in the control group.

Other studies Benoni et al., [18] Jansen et al., [19] Yamasaki et al., [20] Ekback et al., [21] and Sano et al., [22] was conducted on THR or TKR. The volume of blood loss in the procedures may be lesser or greater than during hip fracture surgery and can be attributed to duration as well procedure, but still results were not dissimilar with our study. Benoni et al administered TXA intravenously before tourniquet release and than 3 hours later in patients undergoing TKR, and reported that the intra and postoperative blood loss were reduced to one -third as a result. However in contrast to elective hip or knee surgery, in hip fracture, the fibrinolytic system is activated by trauma and increased during surgery. so we used a single bolus dose of TXA 15 minutes before the incision followed by the same dose every 3 hours to insure that its clot stabilize the effect would cover the intra and postoperative period.

In agreement with our finding, which were based on a surgical procedure that was of similar duration $\geq 120$ minute Ekback et al. [21] showed that the preoperative blood loss was significantly lower in the TXA treated group than the control group , postoperative drainage bleeding was correspondingly less $(p=0.001)(520 \pm 280$ vs. $920 \pm 410 \mathrm{ml})$.

Jansen et al investigated the effect of TXA on blood loss in 42 patients undergoing total knee arthroplasty. Total blood loss measured at 72 hours was $678 \mathrm{ml}$ in TXA treated group while 1419 $\mathrm{ml}$ in the control group. Blood loss on discharge from PACU was $58 \%$ reduced in the TXA treated group. they also found that at first postoperative day, $\mathrm{Hb}$ concentration, expressed as a fraction of postoperative value was significantly higher in TXA group as compared to control group ( $83 \%$ vs. $73 \%$ respectively : $p<0.01$ ) that itself reflect the blood loss.

Yamasaki et al. in their study on cement less THR found a reduction in total blood loss in TXA treated group $(1349 \pm 478 \mathrm{ml})$ than in the control group $(1646 \pm 469 \mathrm{ml})(p<0.01)$. Their postoperative laboratory finding showed that the hemoglobin and hematocrit values on the first, seventh, and fourteenth postoperative days were significantly higher in TXA group that in the control group. In addition, the hemoglobin and hematocrit values in the TXA group 
recovered to the first preoperative day level by the fourteenth postoperative day.

This study also demonstrates that transfusion requirements also reduced in the study group. A Meta-analysis of nine randomized control trial reveals that use of TXA in TKR significantly reduces the proportion of patients requiring blood transfusion. In another study by Camarasa Godoy and Alvarez, found similar results. Lozano and colleagues found that only $17.6 \%$ patients on TXA received blood transfusion in comparison to $54 \%$ in the control group. This is said that TXA increase hypercoagulability and can lead to change of thromboembolic episodes, but we did not face any abnormal finding. Benoni also suggested that TXA does not affect risk of DVT because it inhibits fibrinolysis in the wound not in circulation [23-28].

In conclusion, the present paired study demonstrated that the administration of TXA given preoperatively reduces the blood loss in the first 24 hours by a highly significant degree in patients undergoing surgeries for hip and femoral fractures as well it causes a significant reduction in postoperative anemia and need for transfusion among these patients. This would in turn, help avoid complications related with transfusion of blood and blood products. However, further investigation is necessary to determine the effectiveness [29]. 


\section{References}

1 Irisson E, Hemon Y, Pauly V, Parratte S, Argenson JN,et al. (2012) Tranexamic acid reduces blood loss and financial cost in primary total hip and knee replacement surgery. Orthop Traumatol Surg RES 98: 477-483.

2 Zhang H, Chen J, Chen F, Que W (2012) The effect of tranexamic acid on blood loss and use of blood products in total knee arthroplasty: a meta-analysis. Knee Surg Sports Traumatol Arthrosc 20: 1742-1752.

3 Zhou XD, Tao LJ, Li J, Wu LD (2013) Do we really need tranexamic acid in total hip arthroplasty? A meta-analysis of nineteen randomized controlled trials. Arch Orthop Trauma Surg133: 1017-1027.

4 George DA, Sarraf KM, Nwaboku H (2015) Single perioperative dose of tranexamic acid in primary hip and knee arthroplasty. Eur J Orthop Surg Traumatol Eur 25: 129-133.

5 Oremus K, Sostaric S, Trkulja V, Haspl M (2014) Influence of tranexamic acid on postoperative autologous blood retransfusion in primary total hip and knee arthroplasty: a randomized controlled trial. Transfusion 54: 31-41.

6 Yang ZG, Chen WP, Wu LD (2012) Effectiveness and safety of tranexamic acid in reducing blood loss in total knee arthroplasty: a meta-analysis. J Bone Joint Surg Am 94: 1153-1159.

7 Memtsoudis SG, Danninger T, Rasul R, Poeran J, Gerner P, et al. (2014) Inpatient falls after total knee arthroplasty: the role of anesthesia type and peripheral nerve blocks. Anesthesiology 120: 551-563.

8 Deyo RA, Cherkin DC, Ciol MA (1992) Adapting a clinical comorbidity index for use with ICD- 9-CM administrative databases. J Clin Epidemiol 45: 613-619.

9 Elixhauser A, Steiner C, Harris DR, Coffey RM (1998) Comorbidity measures for use with administrative data. Med Care 36: 8-27.

10 Ury HK (1975) Efficiency of case-control studies with multiple controls per case: continuous or dichotomous data. Biometrics 31: 643-649.

11 Austin PC (2011) An introduction to propensity score methods for reducing the effects of confounding in observational studies. Multivariate Behav Res 46: 399-424.

12 Austin PC (2009) Balance diagnostics for comparing the distribution of baseline covariates between treatment groups in propensityscore matched samples. Stat Med 28: 3083-3107.

13 Parvizi J, Mui A, Purtill JJ, Sharkey PF, Hozack WJ, et,al. (2007) Total joint arthroplasty: when do fatal or near-fatal complications occur? J Bone Joint Surg Am 89: 27-32.

14 Kirksey M, Chiu YL, Ma Y, Della Valle AG, Poultsides L, et al. (2012) Trends in inhospitalmajor morbidity and mortality after total joint arthroplasty: United States 1998- 2008. Anesth Analg 115: 321-327.

15 Kurtz S, Ong K, Lau E, Mowat F, Halpern M (2007) Projections of primary and revision hip and knee arthroplasty in the United States from 2005 to 2030. J Bone Joint Surg Am 89: 780-785.
16 Memtsoudis SG, Sun X, Chiu YL, Nurok M, Stundner O, et al. (2012) Utilization of critical care services among patients undergoing total hip and knee arthroplasty: epidemiology and risk factors. Anesthesiology 117: 107-116.

17 Ahmed I, Chan JK, Jenkins P, Brenkel I, Walmsley P (2012) Estimating the transfusion risk following total knee arthroplasty. Orthopedics 35: e1465-1471.

18 Mangano DT, Tudor IC, Dietzel C (2006) The risk associated with aprotinin in cardiac surgery. N Engl J Med 354: 353-365.

19 Memtsoudis SG, Della Valle AG, Besculides MC, Esposito $M$, Koulouvaris P,et al. (2010) Risk factors for perioperative mortality after lower extremity arthroplasty: a populationbased study of 6,901,324 patient discharges. J Arthroplasty 25: 19-26.

20 Murkin JM (2009) Lessons learned in antifibrinolytic therapy: the BART trial. Sem Cardiothoracic Vasc Anesth 13: 127-131.

21 Hutton B, Joseph L, Fergusson D, Mazer CD, Shapiro S, et al. (2012) Risks of harms using antifibrinolytics in cardiac surgery: systematic review and network meta-analysis of randomised and observational studies. BMJ 345: e5798.

22 Meybohm P, Herrmann E, Nierhoff J, Zacharowski K. Aprotinin (2013) may increase mortality in low and intermediate risk but not in high risk cardiac surgical patients compared to tranexamic acid and epsilon-aminocaproic acid-a meta-analysis of randomised and observational trials of over 30.000 patients. PloS One 8: e58009.

23 Veien M, Sørensen JV, Madsen F, Juelsgaard P (2002) Tranexamic acid given intraoperatively reduces blood loss after total knee replacement: a randomized controlled study. Acta Anaesthesiol Scand 46: 1206-1211.

24 Kakar PN, Gupta N, Govil P, Shah V (2009) Efficacy and safety of Tranexamic acid in control of bleeding following TKR: a randomized clinical trial. Indian J Anesth 53: 667-671.

25 Orpen NM, Little C, Walker G, Crawfurd EJP (2006) Tranexamic acid reduces early postoperative blood loss after total knee arthroplasty: a prospective, randomized, controlled trial of 29 patients. Knee 13: 106-110.

26 Álvarez JC, Santiveri FX, Ramos I, Vela E, Puig L, Escolano F (2008) Tranexamic acid reduces blood transfusion in total knee arthroplasty even when a blood conservation program is applied. Transfusion 48: 519-525.

27 Lozano M, Basora M, Peidro L, Merino I, Segur JM, (2008) Effectiveness and safety of Tranexamic acid administration during total knee arthroplasty. Vox Sang 95: 39-44.

28 Kazemi SM, Mosaffa F, Eajazi A, Kaffashi M (2010) The effect of Tranexamic acid on reducing blood loss in cementless total hip arthroplasty under epidural anesthesia. Thorofare 33: 17.

29 Huang F, Wu D, Ma G, Yin Z, Wang Q (2014) The use of tranexamic acid to reduce blood loss and transfusion in major orthopedic surgery: a meta-analysis. J Surg Res 186: 318-327. 